\title{
A PROSPECTIVE RANDOMIZED TRIAL COMPARING SEQUENTIAL GANCICLOVIR-HIGH DOSE ACYCLOVIR TO HIGH DOSE ACYCLOVIR FOR PREVENTION OF CYTOMEGALOVIRUS DISEASE IN ADULT LIVER TRANSPLANT RECIPIENTS
}

\author{
Maureen Martin, ${ }^{1,2}$ Rafael Mañez, ${ }^{1}$ Peter Linden, ${ }^{3}$ David Estores, ${ }^{4}$ Julian Torre-Cisneros, ${ }^{1}$ \\ Shimon Kusne, ${ }^{1}$ Linnea Ondick, ${ }^{1}$ Richard Ptachcinski, ${ }^{5}$ William Irish, ${ }^{1}$ David Kisor, ${ }^{5}$ \\ Ilene Felser ${ }^{1}$ Charles Rinaldo, ${ }^{6}$ ANDREi Stieber ${ }^{1}$ John Fung, ${ }^{1}$ MonTo Ho, ${ }^{7}$ \\ Richard Simmons, ${ }^{1}$ aNd ThOMAS StarzI ${ }^{1}$
}

Departments of Surgery, Anesthesiology/Critical Care Medicine, Medicine, and Pathology, Divisions of Gastroenterology and Infectious Disease, and School of Pharmacy, University of Pittsburgh, Pittsburgh, Pennsylvania

\begin{abstract}
Cytomegalovirus disease is an important cause of morbidity following liver transplantation. To date there has not been an effective prophylaxis for CMV disease after liver transplantation. One hundred fortythree patients were randomized to receive either high dose oral acyclovir ( $800 \mathrm{mg} 4$ times a day) alone for 3 months after transplantation (acyclovir group) or intravenous ganciclovir ( $5 \mathrm{mg} / \mathrm{kg}$ twice a day) for 14 days followed by high dose oral acyclovir to complete a 3-month regimen (ganciclovir group). Of 139 patients available for evaluation, 43 of $71(61 \%)$ patients from the acyclovir group developed CMV infection compared with 16 of $68(24 \%)$ from the ganciclovir group (relative risk, 3.69; 95\% confidence interval, 2.07-6.56; $P<0.00001)$. Of those randomized, CMV disease was seen in $20(28 \%)$ of the acyclovir group compared with $6(9 \%)$ of the ganciclovir group (relative risk, $5.11 ; 95 \%$ confidence interval, 2.05-12.75; $P=0.0001$ ). The median time to onset of CMV infection was 45 days in the acyclovir group compared with 78 days in the ganciclovir group $(P=0.004)$. The median time to onset of CMV disease was 40 days in the acyclovir group compared with 78 days in the ganciclovir patients $(P=0.02)$. With respect to primary CMV infection, there was no difference in the rates in the 2 groups, but tissue in. vasive disease and recurrent CMV disease were less frequent in the ganciclovir group. It is concluded that a course of 2 weeks of ganciclovir immediately after transplantation followed by high dose oral acyclovir for 10 weeks is superior to a 12-week course of high dose oral acyclovir alone for prevention of both $\mathrm{CMV}$ infection and CMV disease after liver transplanta. tion. However, the lack of significant effect in seronegative recipients who received grafts from seropositive donors suggests that other strategies are needed to prevent CMV infection in this high risk population.
\end{abstract}

\footnotetext{
${ }^{1}$ Department of Surgery.

${ }^{2}$ Address correspondence to: Maureen Martin. MD, FRCS(C), Chief of Transplantation. Department of Surgery, University of Iowa, Iowa City, IA 52242.

${ }^{3}$ Department of Anesthesiology/Critical Care Medicine.

'Division of Gastroenterology.

${ }^{5}$ School of Pharmacy.

${ }^{6}$ Departments of Medicine and Pathology.

'Division of Infectious Diseaso.
}

Cytomegalovirus remains a major cause of infectious morbidity after solid organ or bone marrow transplantation $(1-3)$. Increased utilization of liver transplantation as the preferred option for patients with end-stage liver disease has led to the recognition of the importance of this viral infection and its profound effect on the clinical course, allograft dysfunction, and length of hospital stay of the transplant recipient $(4-6)$.

Treatment of CMV disease in immunosuppressed recipients poses special problems. Current antiviral therapy suppresses CMV but may fail to cure it, and infection often relapses after treatment is stopped. Although these phenomena may still occur even with CMV prophylaxis, most cases of CMV disease occur within a predictably constant time period after transplantation, usually the first 2 months, which makes effective prophylaxis a clinically useful measure. The precise frequency and severity of CMV infection depends on a number of factors, the most important of which include the native CMV immune status of the recipient, the transmission of the virus from the donor organ, and the nature and intensity of immunosuppression $(7-10)$.

Various methods have been investigated to prevent CMV disease after organ transplantation. Enhancing the immune response by vaccination or by passive immunization has reduced the incidence of CMV disease in renal transplant recipients $(11,12)$. Though passive administration of a high titer CMV immunoglobulin has been reported recently to reduce the incidence of $\mathrm{CMV}$ disease and associated mortality after liver transplantation, it was not commercially available when this trial was performed (13). Despite the lack of therapeutic activity against CMV, high dose intravenous or oral acyclovir has been reported to prevent CMV disease in renal and bone marrow transplant patients without adverse effects on patient or graft survival $(14,15)$. Although no similar prospective trials have been reported in liver transplant recipients, an uncontrolled study showed no decrease in CMV disease with high dose oral acyclovir. In contrast, a 1-week course of ganciclovir followed by high dose oral acyclovir for 3 months reduced the rate of CMV disease but did not eliminate it (16).

In this prospective randomized trial, we compared the efficacy and safety of a sequential course of ganciclovir and high dose acyclovir with high dose acyclovir alone for the 
prevention of CMV disease in a population of adult patients undergoing liver transplantation.

\section{MATERIALS AND METHODS}

Randomization and study protocol. This prospective randomized trial was conducted at the University of Pittsburgh Medical Center after approval by the Committee on the Use of Human Subjects in Research. Recipients who were at least 18 years of age were eligible for participation. Patients with fulminant hepatic failure, and/or stage 3 or 4 hepatic coma and those patients with underlying hepatic malignancies who received preoperative chemotherapy were excluded so as to minimize potential additive toxicities.

Although a placebo arm would have been desirable, it was considered unethical. Since ganciclovir is a potent inhibitor of CMV, using it for more than 1 week should suppress CMV for a longer period of time. Despite the lack of an established regimen for CMV prophylaxis in liver transplantation at the time of the trial, and the clear differences between liver and kidney transplantation, it was thought that all patients should receive at least high dose acyclovir, the prophylactic regimen demonstrated to be useful in renal transplant recipients.

Once informed consent was obtained, patients were assigned to be started on either acyclovir or ganciclovir according to a fixed-block randomization scheme (block size $=4$ ). No initial stratification for CMV risk factors was done.

Acyclovir (Burroughs Wellcome Co, Research Triangle Park, NC) was provided in $200-\mathrm{mg}$ capsules with the initial dose given in the intensive care unit by nasogastric tube. Subsequent oral dose adjustments were based on the patient's estimated creatinine clearance rate as follows: $>80 \mathrm{ml} / \mathrm{min}, 800 \mathrm{mg} 4$ times daily; $50-79 \mathrm{mV} / \mathrm{min}, 800$ $\mathrm{mg} 3$ times daily; $10-50 \mathrm{mV} / \mathrm{min}, 800 \mathrm{mg}$ twice daily; and $<10 \mathrm{ml} / \mathrm{min}$, $800 \mathrm{mg}$ once daily.

Ganciclovir (Syntex, Palo Alto, CA) was administered intravenously for 14 days in a dose adjusted to the estimated creatinine clearance rate: $>80 \mathrm{ml} / \mathrm{min}, 5 \mathrm{mg} / \mathrm{kg}$ twice daily; $50-79 \mathrm{mV} / \mathrm{min}, 2.5$ $\mathrm{mg} / \mathrm{kg}$ twice daily; $10-50 \mathrm{mV} / \mathrm{min}, 2.5 \mathrm{mg} / \mathrm{kg}$ once daily; $<10 \mathrm{ml} / \mathrm{min}$, $1.25 \mathrm{mg} / \mathrm{kg}$ once daily. Patients then received 10 weeks of high dose oral acyclovir to complete 12 weeks of therapy. Initiation of either drug was done to allow for stabilization of both patient and graft function within $48 \mathrm{hr}$.

Our analysis addressed the period from study entry to 24 weeks, which encompassed the initial 12 weeks of prophylaxis and a subsequent 12-week follow-up period to allow for the detection of CMV infection and disease occurring late and to assess the effects of treatment on early patient and graft survival.

Clinical management and immunosuppression. Patients underwent OLT according to the standard procedure at the University of Pittsburgh (17). Biliary tract anastomosis was done either by choledochocholedochostomy, or Roux-en-Y choledochojejunostomy. Initial immunosuppression protocols included FK506 (Fujisawa Pharmaceuticals, Osaka, Japan) or CsA (Sandoz, East Hanover, NJ) as described previously (18). Subsequent adjustments of immunosuppressive dose were dictated by the quality of the graft, the presence of rejection, and the plasma levels and/or toxicity of FK506 or CsA. Rejection episodes were treated by $1 \mathrm{~g}$ of methylprednisolone and/or a 5-day taper from $200 \mathrm{mg}$ to $20 \mathrm{mg}$. If necessary, OKT3 (Ortho Pharmaceuticals, Raritan. NJ) was used to treat steroid-resistant rejection. None of the patients received either standard immunoglobulin or CMV hyperimmune globulin.

Weekly clinical and laboratory evaluations, including virologic studies, were done for 3 months, and then at monthly intervals for 6 months. In addition, patients were evaluated twice weekly during any subsequent hospital admission. Any signs or symptoms suggestive of CMV infection (e.g., fever, headaches, malaise, myalgia) or findings localized to the liver. lungs, gastrointestinal tract, or central nervous system were recorded and appropriate inveetigations were carried out.
Laboratory tests. At the time of enrollment, the following indices were measured: hemoglobin level and hematocrit, platelet, reticulocyte, and differential white blood cell counts; serum creatinine and blood urea nitrogen; and serum aminotransferases, alkaline phosphatase, total bilirubin, and albumin.

Virologic and serologic studies. Donor and recipient CMV IgG and IgM antibody titers were measured on all patients by a semiautomated immunofluorescence test (FLAX test system; Whittaker Bioproducts, Inc., Waltersville, MD). Only 2 donor sera were not tested. IgG CMV antibody titers > 20 were considered positive. IgM CMV antibody was reported as negative, equivocal, or positive. Serum samples for antibodies to CMV and specimens from urine, throat swabbing, and blood buffy coat were cultured for CMV by conventional cell culture methods and by shell-vial assay for early CMV antigen detection (19). Weekly samples for CMV cultures and serology were taken during the first 3 months after transplantation, and monthly samples were taken for 3 more months. Additional cultures and serum samples were taken during any subsequent hospital admission or clinical illness.

Definitions and study endpoints. The primary endpoints of this study were the development of CMV disease or death. The protocol drugs were withdrawn if symptomatic CMV infection developed or if toxic reactions occurred.

Primary CMV infection was defined by either seroconversion, a positive shell-vial assay, or the isolation of virus in a cultured specimen from any site in a patient who was seronegative before transplantation. Only 1 patient seroconverted without a positive culture. To exclude the effect of passively transfused antibodies, we used only sera collected more than 30 days after transplantation to document changes in antibody titer. Secondary CMV infection included either reactivation or reinfection and was diagnosed by isolation of virus from any site in a seropositive recipient. CMV disease or symptomatic CMV infection was defined by the following: CMV viral syndrome, localized invasive CMV disease. or disseminated CMV disease. The diagnosis of CMV viral syndrome required laboratory documentation of CMV infection along with fever $>38^{\circ} \mathrm{C}$ for 2 or more days in the absence of another cause, combined with one of the following findings: atypical lymphocytosis > 3\%; white blood cell count $<4,000 / \mathrm{mm}^{3}$; or platelets $<100,000 / \mathrm{mm}^{3}$. Localized CMV dis. ease was defined as tissue invasion in a single organ determined histopathologically and/or by isolation of virus from a tissue specimen. Disseminated CMV disease was defined as invasive involvement of 2 or more tissues at noncontiguous sites.

Statistical methods. The total sample size was calculated to allow the detection of a $50 \%$ reduction in CMV infection among the ganciclovir-treated patients, assuming an infection rate of $60 \%$, an alpha error of 0.05 (two-sided), and a beta error of 0.20 . Time to CMV infection and CMV disease was calculated from the date of trans. plantation to the date of infection and disease, respectively. The cumulative rate of CMV infection and the cumulative rate of symptomatic CMV infection were estimated using the Kaplan-Meier method (20). These rates were then plotted for patient estimates of the infection-free and CMV disease-free in both acyclovir and ganciclovir groups.

Comparison between the incidence of CMV infection and disease in both treatment groups was made using Cox's proportional hazards model, as was the univariate and multivariate analyais of risk factors for CMV infection and CMV disease. Relative risk of CMV in. fection and disease was computed and $95 \%$ confidence interval was generated via Cox's regression. The factors analyzed included age, type of CMV prophylaxis, donor and recipient serologic status, blood products transfused, number of rejection episodes, number of steroid boluses, OKT3 therapy, United Network of Organ Sharing (UNOS)* classification, and the type of bile tract anastomosis. The likelihood ratio chi-square test was used to asses the risk of each factor for CMV

\footnotetext{
* Abbreviations: FFP, fresh-frozen plasma; UNOS, United Net. work of Organ Sharing.
} 
infection and CMV disease. Based on the results of these univariate analyses, we then performed a multivariate analysis. Variables were chosen to be included in the multivariate analysis if they had a $P$-value $<0.25$. The backward elimination method was used as a variable selection technique using the likelihood ratio chi-square test as a means to assess each factor. Variables were entered or excluded from the model based on a $P$-value for entry of 0.10 and a $P$-value for exclusion of 0.15 . Both pretransplant donor-recipient serology and UNOS classification were analyzed as indicator variables using negative-donor/negative-recipient serologic status and UNOS classification of 2 as reference categories. Approximate 95\% confidence intervals were generated for each relative risk.

Baseline characteristics of the patient population were compared between the 2 groups using the standard two-sample $t$ test for continuous data and the Pearson chi-square test for categorical data. All tests of significance were two-tailed. A $P$-value of 0.05 or less was considered to indicate statistical significance.

\section{RESULTS}

Patient enrollment and randomization. Between February 1, 1991, and August 31,1991, 143 patients were enrolled in the study. Four patients were excluded from final analysis for the following reasons: active CMV infection at the time of enrollment ( 1 patient), death from bacterial sepsis and multiorgan failure at 2 weeks and 3 weeks, respectively ( 2 patients), and failure to receive study drug due to institution of early postoperative chemotherapy ( 1 patient). One patient was randomized to ganciclovir but inadvertently received acyclovir and was included in the acyclovir analysis.

Sixty-nine acyclovir group patients $(97 \%)$ and 62 ganciclovir group patients $(91 \%)$ took the assigned drug for 12 weeks or reached a study endpoint. Eight patients $(6 \%)$ did not complete a full drug protocol, of whom 6 were in the ganciclovir group and 2 were in the acyclovir group. One patient received 14 days of ganciclovir and failed to receive high dose oral acyclovir; two patients completed 14 days of ganciclovir and only 1 month of high dose oral acyclovir. Three patients had ganciclovir stopped due to neutropenia ( 1 patient) and neurotoxicity ( 2 patients). In the acyclovir group, 1 patient, after only 1 month of acyclovir, was found to have symptomatic bilateral iliac artery aneurysms requiring aortofemoral bypass. Acyclovir was not resumed after surgery. In another patient, acyclovir was stopped due to neurotoxicity.

Patient characteristics. The final analysis included 139 patients: 71 in the acyclovir group and 68 in the ganciclovir group. The 2 groups were comparable with respect to: age; sex; number of transplants received: type of bile tract anastomosis; proportion receiving immunosuppression with FK506, CsA, or OKT3; number of rejection episodes and steroid boluses; CMV status of the donor and recipient at the time of transplantation; number of units of packed red cells, platelets, and fresh-frozen plasma (FFP) received; and UNOS classification (Table 1).

Overall clinical outcome. One-year patient survival was 83\% (79.5\% ganciclovir group; $83 \%$ acyclovir group), while graft survival was $77 \%$ (77.5\% ganciclovir group; $76.5 \%$ acyclovir group). During the first 6 months after liver transplantation. 59 patients $(42 \%)$ developed CMV infection. Of these patients, 33 remained asymptomatic $(56 \%)$ while 26 patients (44\%) developed CMV disease.

Mortality was not significantly different between the 2 groups. Thirteen patients died (9.3\%) a median of 42 days from the time of transplant (range, 32-180 days). Although
TABLE 1. Demographics and clinical characteristics of patients

\begin{tabular}{|c|c|c|}
\hline & $\begin{array}{l}\text { Acyclovir group } \\
(n=71)\end{array}$ & $\begin{array}{l}\text { Ganciclovir group } \\
(n=68)\end{array}$ \\
\hline \multicolumn{3}{|l|}{ Characteristics } \\
\hline $\operatorname{Sex}(M / F)$ & $35 / 36$ & $43 / 25$ \\
\hline Age $($ mean $=1 \mathrm{SD})$ & $47 \pm 12.9$ & $48.1 \pm 13.2$ \\
\hline Previous transplant & 1 & 1 \\
\hline Choledochocholedochotomy & 44 & 42 \\
\hline Roux-en-Y choledochojejunostomy & 27 & 26 \\
\hline \multicolumn{3}{|l|}{ UNOS classification } \\
\hline 2 Home & 14 & 15 \\
\hline 3 Hospital & 31 & 26 \\
\hline $4 \mathrm{ICU}$ & 26 & 27 \\
\hline \multicolumn{3}{|l|}{ CMV serological status } \\
\hline \multicolumn{3}{|l|}{ Donor/recipient } \\
\hline Positive/negative & 11 & 7 \\
\hline Negative/negative & 6 & 7 \\
\hline Positive/Positive & 30 & 25 \\
\hline Negative/Positive & 24 & 27 \\
\hline Donor not tested & 0 & 2 \\
\hline \multicolumn{3}{|l|}{ Immunosuppression } \\
\hline FK506 & 68 & 63 \\
\hline CsA & 3 & 5 \\
\hline \multicolumn{3}{|l|}{ Biopsy-proven rejection episodes } \\
\hline None & 27 & 23 \\
\hline 1 & 40 & 39 \\
\hline$>1$ & 5 & 6 \\
\hline \multicolumn{3}{|l|}{ Additional immunosuppression } \\
\hline \multicolumn{3}{|l|}{ Steroid Bolus } \\
\hline None & 23 & 19 \\
\hline 1 & 30 & 38 \\
\hline$>1$ & 15 & 14 \\
\hline OKT3 & 3 & 3 \\
\hline \multicolumn{3}{|l|}{$\begin{array}{c}\text { Blood products transfused } \\
\text { (mean } \pm 1 \mathrm{SD})\end{array}$} \\
\hline Packed red cells & $30.2 \pm 28.1$ & $34.8 \pm 31$ \\
\hline Platelets & $48.9 \pm 61.9$ & $50.1 \pm 88$ \\
\hline Fresh-frozen plasma & $24.1 \pm 25.3$ & $28.7 \pm 30.1$ \\
\hline
\end{tabular}

not a direct cause of death in any patient, symptomatic CMV infection preceded death in 4 of 5 acyclovir group patients compared with only 1 of 8 ganciclovir group patients. Causes of death included: liver failure ( 1 patient), bacterial sepsis and multisystem organ failure ( 8 patients), fungal sepsis ( 1 patient), accelerated rejection ( 1 patient), acute myocardial infarction ( 1 patient), and sudden respiratory arrest ( 1 patient). Twelve grafts failed ( 9 in acyclovir group and 3 in ganciclovir group) in a median time of 19 days after transplantation (range, 1-62 days). All 12 patients subsequently underwent retransplantation.

Comparison of acyclovir and ganciclovir groups on the incidence of $C M V$ infection. A mean number of 34 cultures for CMV (range, 12-120) were obtained from each patient. CMV was isolated in 43 of 71 acyclovir group patients $(61 \%)$ compared with 16 of 68 ganciclovir group patients (24\%), a significant reduction (Table 2). There was no significant difference in primary CMV infection in groups receiving acyclovir

TABLE 2. Incidence of asymptomatic and symptomatic CMV infection in acyclovir and ganciclovir groups ${ }^{a}$

\begin{tabular}{lcccccc}
\hline $\begin{array}{c}\text { CMV } \\
\text { infection }\end{array}$ & $\begin{array}{c}\text { Acyclovir } \\
\text { group } \\
(\mathrm{n}=71)\end{array}$ & $\begin{array}{c}\text { Ganciclovir } \\
\text { group } \\
(\mathrm{n}=68)\end{array}$ & $\begin{array}{c}\text { Relative } \\
\text { risk }\end{array}$ & $95 \% \mathrm{CI}$ & $P$ \\
\hline Asymptomatic & $23(32 \%)$ & $10(15 \%)$ & 3.24 & $1.57,6.65$ & 0.0007 \\
Symptomatic & $20(28 \%)$ & $6(9 \%)$ & 5.11 & $2.05,12.75$ & 0.0001 \\
\hline
\end{tabular}

- All patients had CMV infection but one had positive CMV culturea, as did all pationte with CMV disease. 
alone or ganciclovir followed with acyclovir (65\% v8. 50\%) (Table 3). The greatest effect of early ganciclovir prophylaxis was on the reduction of CMV infection in seropositive patients (secondary infection regardless of donor serology). The rate was $59 \%$ in the acyclovir group in contrast to $17 \%$ in the ganciclovir group (Table 3).

Seroconversion was noted in all but 1 of 12 seronegative patients who developed CMV infection. One patient assigned acyclovir remained seronegative despite 2 documented episodes of culture-positive CMV disease.

Comparison of acyclovir and ganciclovir groups on the incidence of CMV disease. Asymptomatic CMV infection was noted in 23 (32\%) acyclovir group patients compared with 10 (15\%) ganciclovir group patients (relative risk, 3.24; $P=0.0007$ ), while CMV disease was seen in 20 (28\%) acyclovir group patients and $6(9 \%)$ ganciclovir group patients (relative risk, 5.11; $P=0.0001$ ) (Table 2). Although CMV syndrome was the most frequent clinical manifestation in both groups, striking differences in the patterns of tissue invasive disease were noted between the serologic subgroups (Table 4). Localized CMV disease (pneumonitis, hepatitis, or gastrointestinal disease) was seen in 11 acyclovir group patients compared with 2 ganciclovir group patients. No ganciclovir group patient developed CMV pneumonia. In contrast, 5 acyclovir group patients had CMV pneumonia and all required mechanical ventilation. Two such patients subsequently died from bacterial ( 1 patient) or fungal ( 1 patient) infection, and autopsy in these patients failed to demonstrate residual CMV disease. Four of 5 patients with CMV hepatitis received acyclovir alone. No graft loss could be related directly to CMV disease.

Comparison of acyclovir and ganciclovir groups on the incidence of viremia. Viremia was noted in a total of $26 \mathrm{CMV}$ infected patients (44\%). In the patients who developed infection, CMV was recovered in blood from $37.5 \%$ of ganciclovir group patients and $46.5 \%$ of acyclovir group patients. Viremia without symptomatic CMV infection was noted in $6 \mathrm{pa}$ tients (5 acyclovir group, 1 ganciclovir group), while localized disease without viremia was noted in 6 patients ( 5 acyclovir group, 1 ganciclovir group).

Timing of CMV infection. The median time from transplantation to CMV infection was 45 days (range, 17-151 days) in the acyclovir group compared with 78 days (range, 19-144 days) in the ganciclovir group ( $P=0.004)$ (Fig. 1$)$. The median time to CMV disease was 40 days (range, 19-140 days) in the acyclovir group compared with 78 days (range, 54-95 days) in the ganciclovir group ( $P=0.02$ ) (Fig. 2).

The median time to primary infection was 39 days (range, 22-56 days) in the acyclovir group compared with 77 days (range, 54-92 days) in the ganciclovir group $(P=0.0003)$. The median time to secondary infection was 49 days (range, 17151 days) in the acyclovir group and 81 days (range, 19-144 days) in the ganciclovir group $(P=0.1)$.
Recurrent CMV disease. All patients who subsequently developed CMV disease in this trial, regardless of study drug assignment, were treated with a 14-day course of ganciclovir. Five patients, however, developed recurrent CMV disease at a median of 101 days (range, 62-203 days) after transplantation and 61 days (range, 36-157 days) after the first episode of CMV disease. Four of 5 patients with recurrent CMV disease belonged to the acyclovir group. In addition, 4 were seronegative patients who received seropositive allografts. Only 1 seronegative patient who received a seropositive graft had recurrent CMV disease in the ganciclovir group. Thus, counting initial and recurrent episodes of primary CMV disease (Table 4), there were 11 episodes in the acyclovir group and 5 episodes in the ganciclovir group (NS). These patients responded promptly to a second course of ganciclovir. No further recurrent CMV disease has been observed at a minimum of 1-year follow-up in any patient.

Risk factors for CMV infection and CMV disease. CMV infection and $\mathrm{CMV}$ disease result from a complex interplay between various possible factors. After screening by univariate analysis of factors listed in Materials and Methods, a multivariate Cox regression analysis for CMV infection and disease was done. The result was that prophylaris with acyclovir alone $(P<0.00001)$, and donor-seropositive/recipientseronegative matches $(P<0.007)$ were risk factors associated with CMV infection (Table 5). When CMV disease was considered, the multivariate analysis demonstrated prophylaxis with acyclovir alone $(P=0.005)$ and transfusion of more than $30 \mathrm{U}$ of packed $\mathrm{RBCs}(P=0.01)$ to be associated with an increased risk for CMV disease. The donor-seropositive/recipient-seronegative combination demonstrated a borderline statistical risk for developing CMV disease $(P=0.06)$.

Risk factors for primary and secondary CMV infection. The multivariate Cox proportional hazards model was used to analyze the same variables described above while controlling for recipient pretransplant serologic status. For seronegative recipients, this analysis showed that donor seropositivity $(P=0.006)$, and the number of units of FFP transfused $(P=0.04)$ were associated with infection (Table 6). Neither ganciclovir followed by high dose acyclovir nor high dose acyclovir alone exerted a protective effect for primary CMV infection $(P=0.2)$.

For seropositive recipients, this analysis showed that prophylaxis with acyclovir alone $(P<0.00001)$ was the sole variable found to be associated with secondary CMV infection. A borderline statistical risk for secondary CMV infection was noted when the presence of rejection episodes was considered $(P=0.07)$.

Adverse effects. Severe neutropenia (neutrophil count < $1000 / \mathrm{mm}^{3}$ ) was observed in 1 ganciclovir group patient after 10 days of therapy. Ganciclovir was discontinued and high dose oral acyclovir was begun 3 days later to complete the

TABLE 3. Incidence of CMV primary and secondary infection in acyclovir and ganciclovir groups ${ }^{\circ}$

\begin{tabular}{|c|c|c|c|c|c|}
\hline $\begin{array}{c}\text { CMV } \\
\text { infoction }\end{array}$ & $\begin{array}{c}\text { Acyclovir } \\
\text { group } \\
(\mathrm{n}=71)\end{array}$ & $\begin{array}{c}\text { Ganciciovir } \\
\text { group } \\
(\mathrm{n}=68)\end{array}$ & $\begin{array}{l}\text { Rolative } \\
\text { risk }\end{array}$ & $96 \% \mathrm{CI}$ & $P$ \\
\hline $\begin{array}{l}\text { Primary infection } \\
\text { Secandary infection }\end{array}$ & $\begin{array}{l}11 / 17(65 \%) \\
32 / 34(59 \%)\end{array}$ & $\begin{array}{l}7 / 14(50 \%) \\
9 / 32(17 \%)\end{array}$ & $\begin{array}{l}1.94 \\
4.89\end{array}$ & $\begin{array}{c}0.76,5.03 \\
2.33,10.27\end{array}$ & $\begin{array}{c}0.2 \\
<0.00001\end{array}$ \\
\hline
\end{tabular}

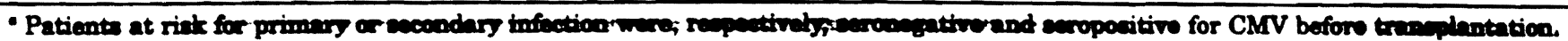


TABLE 4. Manifestations of CMV disease according to pretransplant donor and recipient serology

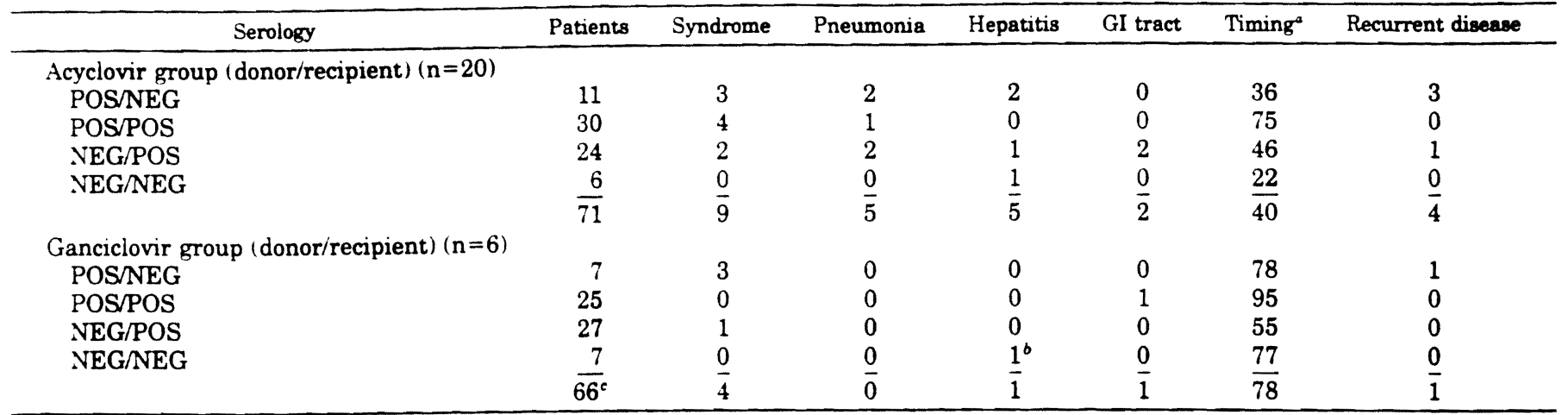

aedian time to first episode of CMV disease.

${ }^{b}$ Also gastrointestinal involvement.

'Two donor serologies were not available.

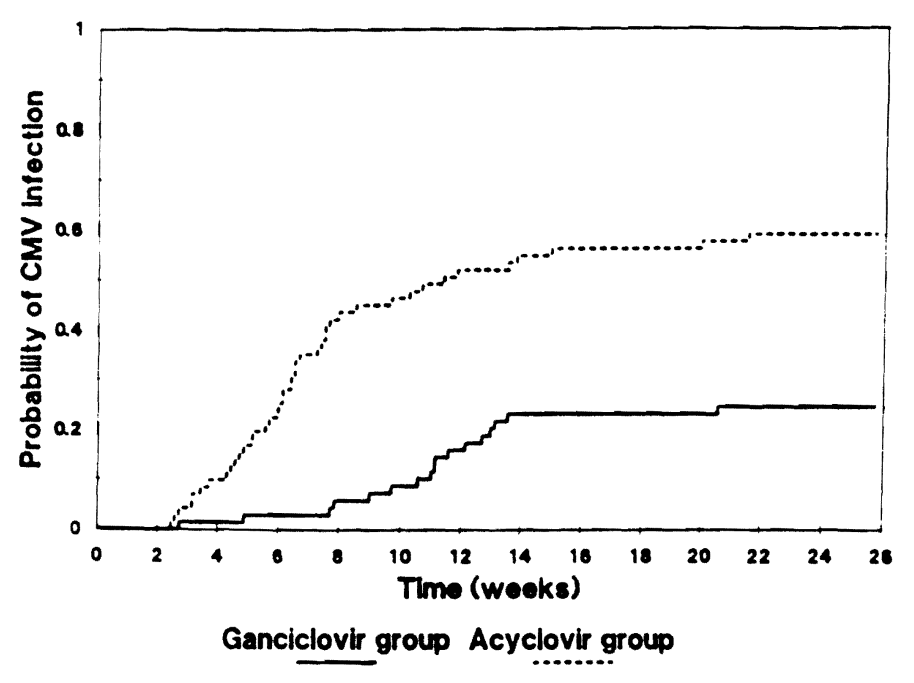

FIGURE 1. Probability of developing CMV infection in acyclovir and ganciclovir groups.

3-month regimen. Neurotoxicity was seen in 3 patients in the first week after transplantation ( 2 ganciclovir group patients, 1 acyclovir group patient). These patients developed confusion and lethargy, with no focal lesions found on neurologic evaluation. Prompt improvement was seen after withdrawal of treatment drugs and no permanent neurologic sequelae have been noted.

\section{DISCUSSION}

This prospective, randomized trial demonstrates that prophylactic ganciclovir in the early posttransplant period followed by high dose acyclovir provides substantial protection from CMV infection and disease in adult liver transplant recipients without adversely affecting either patient or graft survival. In addition. the significant delay to the onset of both primary and secondary CMV infection noted in ganciclovir patients avoided the critical period when surgical complications. immunosuppression, and acute rejection were most intense. This benefit is further enhanced by the fact that CMV infection, even without disease, exerts an immunosuppressant effect that increases the incidence of other opportunistic infections (21).

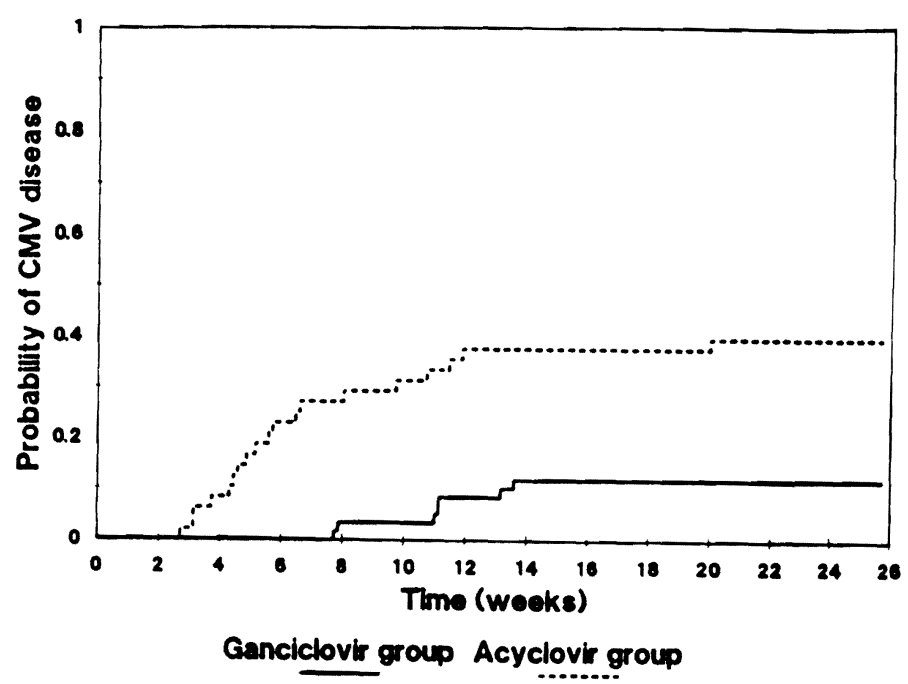

FIGURE 2. Probability of developing CMV disease in acyclovir and ganciclovir groups.

TABLE 5. Multivariate analyBis of risk factors for CMV infection and CMV disease using Cox proportional hazards model

\begin{tabular}{lccc}
\hline \multicolumn{1}{c}{ Risk factor } & Relative risk & $95 \% \mathrm{CI}$ & $P$ \\
\hline $\begin{array}{c}\text { CMV infection } \\
\text { High dose acyclovir alone } \\
\text { prophylaxis }\end{array}$ & 3.31 & $(1.86,5.90)$ & $<0.00001$ \\
$\begin{array}{c}\text { Donor-positive/recipient- } \\
\text { negative status }\end{array}$ & 4.84 & $(1.39,16.86)$ & 0.013 \\
$\begin{array}{c}\text { CMV disease } \\
\text { High dose acyclovir alone } \\
\text { prophylaxis }\end{array}$ & 3.98 & $(1.52,10.39)$ & 0.0046 \\
$\begin{array}{c}\text { Transfusion of > 30 U of } \\
\text { packed red cells }\end{array}$ & 4.84 & $(1.23,6.37)$ & 0.014 \\
\hline
\end{tabular}

Along with a $60 \%$ reduction in the incidence of $\mathrm{CMV}$ infection, early prophylaxis with ganciclovir resulted in a $68 \%$ reduction in CMV disease. Furthermore, only 2 ganciclovir group patients developed tissue invasive disease compared with 11 patients who received high dose acyclovir alone. The prophylactic efficacy of early ganciclovir was also supported by the finding that no patient developed pneumonia compared with 5 patients in the acyclovir group. There was no difference in the rate of CMV viremia between the etudy groups. However, viremia was observed in only $50 \%$ of pa- 
TABLE 6. Multivariate analysis of risk factors for CMV infection stratified by recipient pretransplant CMV status using Cox proportional hazards model

\begin{tabular}{cccc}
\hline Risk factor & Relative risk & $95 \% \mathrm{CI}$ & $P$ \\
\hline $\begin{array}{c}\text { Primary infection } \\
\text { Donor seropositive }\end{array}$ & 6.00 & $(1.68,21.48)$ & 0.006 \\
FFP transfused (U) & 1.04 & $(1.00,1.07)$ & 0.043 \\
$\begin{array}{c}\text { Secondary infection } \\
\text { High dose acyclovir } \\
\text { alone prophylaxis }\end{array}$ & 4.80 & $(2.28,10.11)$ & $<0.00001$ \\
\hline
\end{tabular}

tients with tissue invasive disease. This is in contrast to previous reports in which viremia was associated with virtually all cases of CMV disease (22) and suggests that both antiviral agents may in fact influence the recovery rate of CMV from blood samples obtained during CMV disease. The multivariate analysis identified the use of high dose acyclovir alone and donor-seropositive/recipient-seronegative combinations as risk factors for development of both CMV infection and CMV disease. Additionally, transfusion of more that $30 \mathrm{U}$ of packed red cells increased the risk for CMV disease but not infection. Although CMV-screened blood was not used routinely in our trial, this result is consistent with recent data from our center suggesting that blood transfusions increase the probability of CMV pneumonia during primary infection following liver transplantation (23). It is unclear how multiple blood transfusions act; possibly, they increase the CMV viral inoculum or somehow alter cellular immunity.

CMV-related death was not seen in either group. However, CMV disease preceded death in 4 out of $5(80 \%)$ acyclovir group patients compared with 1 out of $8(13 \%)$ ganciclovir group patients. These results are in agreement with previous studies in which high mortality was observed when CMV disease preceded serious bacterial and fungal infections (24).

In this trial, neither high dose acyclovir alone nor sequential ganciclovir-high dose acyclovir reduced the rate of primary infection, although infection was postponed by ganciclovir. Despite failure to reduce primary infection or CMV viral syndrome by ganciclovir, only 1 seronegative patient from the ganciclovir group developed tissue invasive disease, while there were 5 such patients from the acyclovir group. This reduction in severity of CMV disease during primary infection in the ganciclovir group may not have reached significance because of small numbers. It may be related to delaying infection beyond the early posttransplant critical period, when immunosuppression requirements are greatest. The lack of effect of either prophylaxis regimen studied here in the prevention of primary infection is consistent with observations in lung transplant, pediatric liver recipients and heart recipients (25-27). In contrast, high dose oral acyclovir has been reported to be effective in preventing primary CMV infection in kidney transplant recipients. The disparity between these results may relate to basic differences in the spectrum and severity of CMV disease in the different organ transplant populations, or to the varying immunosuppression drug regimens used $(28-30)$.

The significant risk factors for primary infection in the multivariate analysis were donor seropositive status and units of FFP transfused. It was particulariy surprising that FFP, a virtually cell-free component, was associated with a high risk of primary CMV infection. However, in a recent study, CMV DNA was isolated from plasma of AIDS patients, suggesting that plasma may also transmit CMV (31).

The relationship between $\mathrm{CMV}$ infection and allograft rejection is complex. The majority of patients in this trial received FK506. In our institution, FK506 has reduced the need for repeated steroid boluses and antilymphocytic agents such as OKT3 to treat rejection (32). Despite a decrease in bacterial and fungal infections observed during our randomized FK506/CsA trial, the incidence of CMV disease was unchanged, suggesting that other factors are perhaps more important in liver transplant recipients (32). The number of patients receiving CsA in our study was too small to assess whether differences in the rates of CMV infection were influenced by the type of immunosuppression. Rejection was a borderline statistical risk factor for secondary CMV infection. However, early ganciclovir prophylaxis may have eliminated any statistical association between rejection and secondary infection.

Both drugs regimens were well tolerated, with only a rare occurrence of hematologic and neurologic side effects. True bone marrow depression was observed in only 1 patient (1.5\%) and this was easily reversed once ganciclovir was discontinued. The issue of drug absorption and dosing is an important factor when comparing our patients with other solid organ recipients; disturbances of gastrointestinal tract function and motility are frequent following liver transplantation. The transplant operation itself, the type of biliary tract reconstruction, together with the common postoperative intra-abdominal problems exert an important effect on drug absorption. Whether administering acyclovir intravenous to assure bioavailability would have altered our findings remains unknown. The incidence of CMV infection in our patients, however, was not affected by the type of biliary tract anastomosis.

The incidence of infection after prophylaxis with high dose oral acyclovir alone was similar to previous reports of CMV infection from our institution when CMV prophylaxis was not given (33). Also, most cases of CMV infection and disease appeared during the period of ongoing acyclovir therapy. Furthermore, a recent innovative trial conducted by Singh et al. (34) comparing high dose acyclovir to "preemptive" ganciclovir at the time of viral shedding demonstrated similar rates of infection in the acyclovir arm. Another study reported by Snydman et al. (35) noted a virtually identical infection and disease rate in their placebo patients. This raises serious doubt as to whether acyclovir has any effect by itself or following the early course of ganciclovir. The effectiveness of 2 weeks of ganciclovir alone, however, remains to be studied. Of concern is the recent observation that ganciclovir for 1 week combined with human immunoglobulin was less effective than high dose acyclovir in a large randomized trial of organ transplant patients (predominantly renal transplant patients) at the University of Minnesota (36).

In the setting of liver transplantation, this trial supports the use of an early, short course of intravenous ganciclovir to reduce CMV infection and CMV disease. It is unclear whether the subsequent use of high dose acyclovir contributed to the benefit observed. The decreased effectiveness of this protocol in the donor-seropositive/recipient-seronegative population emphasizes the need for new strategies to prevent primary infection. 


\section{REFERENCES}

1. Ho $\mathrm{M}$ (Ed). Human cytomegalovirus infection in immunosuppressed patients. In: Cytomegalovirus: biology and infection. New York: Plenum Medical, 1991: 249.

2. Dummer JS, White LT, Ho M, Griffith BP, Hardesty RL, Bahnson HT. Morbidity of cytomegalovirus infection in recipients of heart or heart-lung transplants who received cyclosporine. J Infect Dis 1985; 152: 1182.

3. Reusser P, Fisher LD, Buckner CD, Thomas ED, Meyers JD. Cytomegalovirus infection after autologous bone marrow transplantation: occurrence of cytomegalovirus disease and effect on engraftment. Blood 1990; 75: 1888.

4. Kusne S, Dummer JS, Sing N, et al. Infections after liver transplantation: an analysis of 101 consecutive cases. Medicine (Baltimore) 1988: 67: 132.

5. Rakela J, Wiesner RH, Taswell HF, et al. Incidence of cytomegalovirus infection and its relationship to donor-recipient serologic status in liver transplantation. Transplant Proc 1987; 19: 2399.

6. Rubin RH. Impact of cytomegalovirus infection on organ transplant recipients. Rev Infect Dis 1990; 12 (suppl): S754.

7. Peterson PK, Ferguson R, Fryd DS, Balfour HH, Rynasiewicz J, Simmons RL. Infectious diseases in hospitalized renal transplant recipients: a prospective study of a complex and evolving problem. Medicine (Baltimore) 1982; 61: 360.

8. Ho M. Suwansirikul S, Dowling JN, Youngblood LA. Armstrong JA. The transplanted kidney as a source of cytomegalovirus infection. N Engl J Med 1975; 293: 1109.

9. Ho M, Dowling JN, Armstrong JA, et al. Factors contributing to the risk of cytomegalovirus infection in patients receiving renai transplants. Yale J Biol Med 1976; 49: 17.

10. Singh N, Dummer JS, Kusne S, et al. Infections with cytomegalovirus and other herpes viruses in 121 liver transplant recipients: transmission by donated organ and the effect of OKT3 antibodies. J Infect Dis 1988; 158: 124.

11. Plotkin AS, Starr SE, Friedman HM, Gonezol E, Brayman K. Vaccines for the prevention of human cytomegalovirus infection. Rev Infect Dis 1990; 12 (suppl): S827.

12. Snvdman DR, Werner BG, Heinze-Lacey B, et al. Use of cytomegalovirus immune globulin to prevent cytomegalovirus disease in renal transplant recipients. $\mathrm{N}$ Engl J Med 1987; 317: 1049.

13. Snydman DR, Werner BG, Dougherty NN, et al. Cytomegalovirus immune globulin prophylaxis in liver transplantation. Ann Intern Med 1993; 119: 984.

14. Balfour H Jr, Chace BA, Stapleton JT, Simmons RL, Frid DS. A randomized placebo-controlled trial of oral acyclovir for the prevention of cytomegalovirus disease in recipients of renal allografts. N Engl J Med 1989; 320: 1381.

15. Meyers JD. Reed EC. Shepp DH, et al. Acyclovir for prevention of cytomegalovirus infection and disease after allogenic marrow transplantation. N Engl J Med 1988; 318: 70.

16. Freise CE, Pons V, Lake J, Burke E, Ascher NL, Roberts JP. Comparison of three regimens for cytomegalovirus prophylaxis in 147 liver transplant recipients. Transplant Proc 1991; 23: 1498 .

17. Stieber AC, Makowka L, Starzl TE. Orthotopic liver transplantation. In: Starzl TE, Shapiro R, Simmons RL, eds. Atlas of organ transplantation. New York: Gower Medical Publishing, 1992: 7.1 .

18. Todo S, Fung JJ, Starzl T, et al. Liver, kidney and thoracic organ transplantation under FK506. Ann Surg 1990; 212(3): 295.

19. Gleaves CA. Smith TF, Shuster EA, Pearson GR. Comparison of standard tube and shell vial cell culture techniques for the detection of cytomegalovirus in clinical specimens. J Clin Microbiol 1985; 21: 217.

20. Lee ET. Statistical methods for survival data analysis. Belmont, CA: Wadsworth. Inc., 1980: 76.

21. Rand KH, Merigan TC. Cytomegalovirus, a not so innocent bystander. JAMA 1978; 240: 2470.

22. Gardler H, Tillegard A, Groth CG. Studies of cytomegalovirus infection in renal allograft recipients. I. Virus isolation. Scand $J$ Infect Dis 1982; 14: 81.

23. Mañez R, Kusne S, Martin M, et al. The impact of blood transfusion on the occurrence of pneumonitis in primary cytomegalovirus infection after liver transplantation. Transfusion 1993; 33: 594.

24. Balfour HH Jr (Ed). Prevention and treatment of cytomegalovirus disease. In: Advances in therapy against herpesvirus infections in immunocompromised hosts [symposium proceedings]. Minneapolis: University of Minnesota, 1985: 35.

25. Bailey TC, Trulock EP, Ettinger NA, Storch GA, Cooper JD, Powderly WG. Failure of prophylactic ganciclovir to prevent cytomegalovirus disease in recipients of lung transplants. $J$ Infect Dis 1992; 165: 548 .

26. Jara P, Diaz C, De La Vega L, et al. Ganciclovir prophylaris of cytomegalovirus infection in pediatric patients undergoing liver transplantation: preliminary results. Trasplante 1990; 1 : 63.

27. Merigan TC, Renlund DG, Keay S, et al. A controlled trial of ganciclovir to prevent cytomegalovirus infection after heart transplantation. N Engl J Med 1992; 326: 1182-6

28. Gorensek MJ, Stewart RW, Keys TF, McHenry MC, Goormastic M. A multivariate analysis of the risk of cytomegalovirus infection in heart transplant recipients. J Infect Dis 1988; 157: 515.

29. Rubin RH, Tolkoff-Rubin NE, Oliver D, et al. Multicenter seroepidemiologic study of the impact of cytomegalovirus infection on renal transplantation. Transplantation 1985; 40: 243.

30. Bronsther O, Makowka L. Jaffe R, et al. Occurrence of cytomegalovirus hepatitis in liver transplant patients. J Med Virol 1988; 24: 423.

31. Spector SA, Merrill R, Wolf D, Dankner W. Detection of human cytomegalovirus in plasma of AIDS patients during acute visceral disease. J Clin Microbiol 1992; 30: 235.

32. Fung $J$, Todo S, Tzakis A, et al. Current status of FK506 in liver transplantation. Transplant Proc 1991; 23: 1902.

33. Alessiani M, Kusne S; Martin M, et al. Infections in adult liver transplant patients under FK506 immunosuppression. Transplant Proc 1991; 23: 1501.

34. Singh N, Mieles L, Yu VL. Failure of high dose acyclovir and success of pulse ganciclovir in preventing cytomegalovirus (CMV) disease in liver transplant recipients. A prospective, randomized trial. Abstracts of the 32nd Interscience Conference on Antimicrobial Agents and Chemotherapy, Anaheim, CA, October 1992.

35. Snydman DR, Werner BG, Dougherty NN, et al. Cytomegalovirus immune globulin prophylaxis in liver transplantation. Ann Intern Med 1993; 119: 984.

36. Dunn $D$, Gillingham $K$, Kramer $M$, et al. A prospective randomized study of acyclovir versus ganciclovir plus human immune globulin prophylaxis of cytomegalovirus infection after solid organ transplantation. Transplantation 1994; 57: 876.

Received 2 February 1994.

Accepted 20 April 1994. 